\title{
Novel breeding approach for Japanese flounder using atmosphere and room temperature plasma mutagenesis tool
}

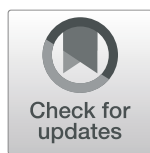

Hou Ji-Lun ${ }^{1,2}$, Zhang Xiao-Yan², Wang Gui-Xing ${ }^{2}$, Sun Zhao-Hui ${ }^{2}$, Du Wei ${ }^{2}$, Zhao Ya-Xian², Si Fei ${ }^{2}$, Wang Li-Yan ${ }^{3}$, Xing Xin-Hui ${ }^{4,5^{*}}$ and Wang Yu-Fen ${ }^{2^{*}}$

\begin{abstract}
Background: Artificial induction of mutagenesis is effective for genetic resource innovation and breeding. However, the traditional mutation methods for fish breeding are not convenient or safe for daily use. Hence, development of a simple, safe and effective mutagenesis method with a high mutation rate and applicability to multiple fish species, is needed.

Results: We reported the first successful mutagenesis in a marine aquaculture fish species, Japanese flounder, Paralichthys olivaceus, using a novel atmosphere and room temperature plasma (ARTP) mutagenesis tool. ARTP treatment time was optimized for the fertilized eggs and sperm, respectively. Eggs fertilized for 60 min were treated by ARTP with a radiofrequency power input of $120 \mathrm{~W}$, and the ARTP treatment time was $25 \mathrm{~min}$. Under an ARTP radio-frequency power input of $200 \mathrm{~W}$, the optimal treatment time for sperm diluted with Ringer's solution by 1:40 V/V was $10 \mathrm{~min}$. The ARTP-treated group presented differences in morphological traits such as body height, total length among individuals at day 90 after hatching. Whole-genome sequencing was used to reveal the mutation features of ARTP-treated individuals collected at day 120 after hatching. In total, 69.25Gb clean data were obtained from three controls and eight randomly selected ARTPtreated individuals, revealing 240,722 to 322,978 SNPs and 82,149 to 86,798 InDels located in 17,394 18,457 and $12,907 \sim 13,333$ genes, respectively. The average mutation rate reached $0.064 \%$ at the genome level. Gene ontology clustering indicated that genes associated with cell components, binding function, catalytic activity, cellular process, metabolic process and biological regulation processes had higher mutation rates.
\end{abstract}

Conclusions: ARTP mutagenesis is a useful method for breeding of fish species to accelerate the selection of economically important traits that would benefit the aquaculture industry, given the variety of mutations detected.

Keywords: ARTP mutagenesis, Japanese flounder, Paralichthys olivaceus, Genome, Breeding

\section{Background}

The purpose of breeding in aquaculture fish is to discover and generate economically important traits such as fast growth, disease resistance or meat quality. No matter which kind of breeding method is used, the successful breeding of improved strains basically depends on the mutations present in the base population. Mutations are the basis of genetic variation, and naturally occurring mutations play

\footnotetext{
*Correspondence: xhxing@mail.tsinghua.edu.cn; wangyf-8000@163.com ${ }^{4}$ Key Laboratory for Industrial Biocatalysis, Ministry of Education, Department of Chemical Engineering, Tsinghua University, Beijing, China

${ }^{2}$ Beidaihe Central Experiment Station, Chinese Academy of Fishery Sciences, Qinhuangdao, China

Full list of author information is available at the end of the article
}

important roles in evolution. In fish, the natural mutation rate at specific loci is generally lower than $1.0 \times 10^{-6}[1]$. Artificially induced mutation in fish usually employs physical radiation or chemical mutagens. One of the widely used chemical mutagens, $N$-ethyl- $N$-nitrosourea (ENU) acts as an alkylating agent, transferring its ethyl group to nucleophilic nitrogen or oxygen sites on deoxyribonucleotides, leading to base mismatching during DNA replication, and thus, it mainly induces single-base substitutions $[2,3]$. The ENU has shown relatively high mutation frequency. When consider the mutation rate that based on specific gene, the mutation rate was 1 per $297 \mathrm{~kb}(0.0003 \%)$ in fugu [1], 1 per $345 \mathrm{~kb}$ in medaka $(0.0003 \%)$ [4], 1 per $235 \mathrm{~kb}$ in zebrafish

(C) The Author(s). 2019 Open Access This article is distributed under the terms of the Creative Commons Attribution 4.0 International License (http://creativecommons.org/licenses/by/4.0/), which permits unrestricted use, distribution, and 
(0.0004\%) [5] and $0.41 \%$ in grass carp (Ctenopharyngodonidellus) [6]. While consider mutation rate of specific loci based on phenotype, the mutation rate was $0.15 \%$ in zebrafish [7] and $0.1 \% \sim 0.195 \%$ in medaka [8].

In addition to chemical mutagens, physical mutagens such as $\gamma$-ray, X-ray, UV, or particle radiation also play important roles in mutation induction [9]. In medaka, a specific locus test system for environmental mutagenesis was established using ${ }^{137} \mathrm{Cs} \gamma$-ray irradiation [10]. Moreover, atmosphere and room temperature plasma (ARTP) is a newly developed mutation system for microbes that uses a helium radio-frequency atmospheric-pressure glow discharge (RF APGD) plasma generator as its core component $[11,12]$. RF APGD can be produced between two water-cooled bare-metallic electrodes driven by a radio-frequency power supply. When working, the plasma gas (helium with purity of $99.99 \%$ or better) flowing through the discharge region between the two electrodes is ionized by the externally applied RF electric field, and thus, a non-thermal plasma jet consisting of various activated chemical particles is formed at the downstream of the plasma torch nozzle exit $[13,14]$. The various activated chemical particles RF APGD can alter DNA sequences by widely broken down the $\mathrm{C}-\mathrm{N}$ bond between base and ribose, amino groups on the base, as well as the P-O bonds in phosphodiester [15]. Moreover, The studies of ARTP mutagenesis indicated that irradiation with ARTP is a rapid, effective, convenient, and multifaceted means of generating mutant libraries with sufficient diversity for the improvement of microbial phenotypes [14, 16, 17]. Mechanistic study on ARTP mutagenesis indicated that ARTP can cause stronger DNA damage and thereby result in higher mutation rate compared with the UV and chemical mutagens $[14,16]$. ARTP has been successfully employed for mutation breeding in more than 100 kinds of microbes [17], including bacteria [18-20], fungi [21, 22], and microalgae [23-25]. However, whether ARTP can be applied to fish mutation breeding is still not clear.

Japanese flounder, Paralichthys olivaceus, is an economically important marine flatfish in China, and its cultural production is estimated to be 30,000 tons per year. The Japanese flounder is also a major target marine fish species for genetic and breeding studies, and many breeding methods such as gynogenesis [26, 27] and androgenesis [28] have been established. In addition, its complete genome sequence has been decoded [29]. However, decrease of Japanese flounder resource in nature, and reducing of genetic diversity in hatchery population limit progress in breeding using traditional methods [30]. Therefore, a new breeding method that could increase genetic variety is urgently needed.

In this study, we applied ARTP as a mutagenesis tool for the first time to generate mutations in Japanese flounder for breeding. The optimal ARTP mutagenesis parameters were established, and the genetic variations of ARTPtreated individuals were analyzed at the genome level using high-throughput sequencing.

\section{Results}

\section{Determination of the ARTP treatment time for fertilized eggs}

To obtain the ARTP treatment time for the fertilized eggs, 60 min after fertilization eggs were irradiated with ARTP for different treatment time periods, and the fertilization rate, hatch rate and abnormal rate were evaluated. As shown in Fig. 1, the fertilization rate ranged from $69.20 \pm$

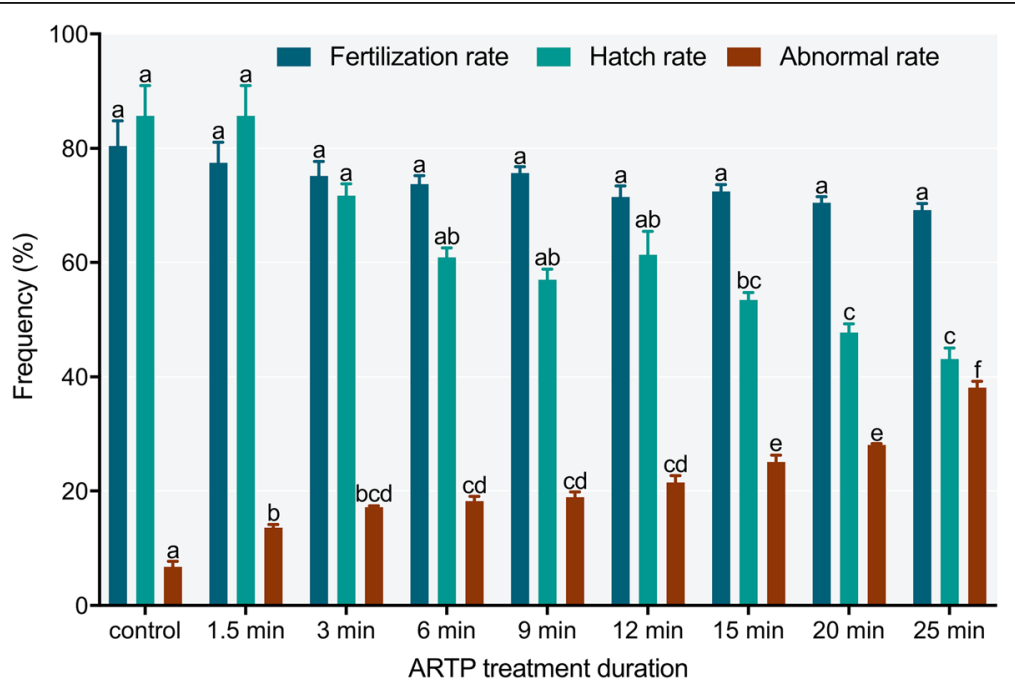

Fig. 1 Effects of treatment duration on the fertilization, hatch and abnormal rates of Japanese flounder, Paralichthys olivaceus, irradiated by atmospheric and room temperature plasma (ARTP). Letters above columns indicate significant differences as determined by one-way ANOVA and LSD multiple comparisons $(P<0.05)$ 
$2.01 \%$ to $80.43 \pm 7.50 \%$, and the difference between each group was not significant $(P>0.05)$. The hatch rates by ARTP treatment for 1.5, 3, 6, 9 and 12 min were not significantly different from each other or that of the control $(P>$ 0.05). However, the hatch rates of 20 and $25 \mathrm{~min}$ ARTP treatment groups were significantly different from the control and the 1.5 to 12 min treatment groups $(P<0.05)$. Each treatment group included various types of abnormal larvae (Fig. 2), and the abnormal rate in each was significantly higher than that in the control group. The $25 \mathrm{~min}$ ARTP treatment group had an abnormal rate of $38.13 \pm 1.92 \%$, which was the highest among the treatment groups. Under an input power of $120 \mathrm{~W}$, the ARTP jets increased the temperature when the treatment time period was longer than $25 \mathrm{~min}$; the higher temperature was not suitable for Japanese flounder embryo development and would lead to excessive evaporation of the seawater used for egg incubation. Considering all these factors, we chose $25 \mathrm{~min}$ as the ARTP treatment time for Japanese flounder eggs.

\section{Determination of the optimal ARTP treatment time period for sperm}

For 1:40 diluted sperm (40X) that were shaded after ARTP treatment, the relative abnormal rate was reduced from 2 to 6 min irradiation, then sharply increased from 8 to 10 min irradiation, and reduced again from 10 to $12 \mathrm{~min}$ irradiation. The $10 \mathrm{~min}$ ARTP treatment group had the highest relative abnormal rate, which was significantly different from those of the other groups $(P<0.05)$; the relative abnormal rates in the 8 and 12 min ARTP treatment groups were not significantly different $(P>0.05)$, but they were significantly higher than that in the 6 min group (Fig. 3). The trend of changes in the relative abnormal rate of $40 \mathrm{X} \mathrm{di-}$ luted sperm that were not shaded after ARTP treatment was similar to that of the shaded sperm; the only difference was that the rate ascended from 2 to 4 min ARTP irradiation and descended from 4 to 6 min irradiation (Fig. 3).

Comparing the shaded and nonshaded treatments of 40X diluted sperm, the relative abnormal rate after the

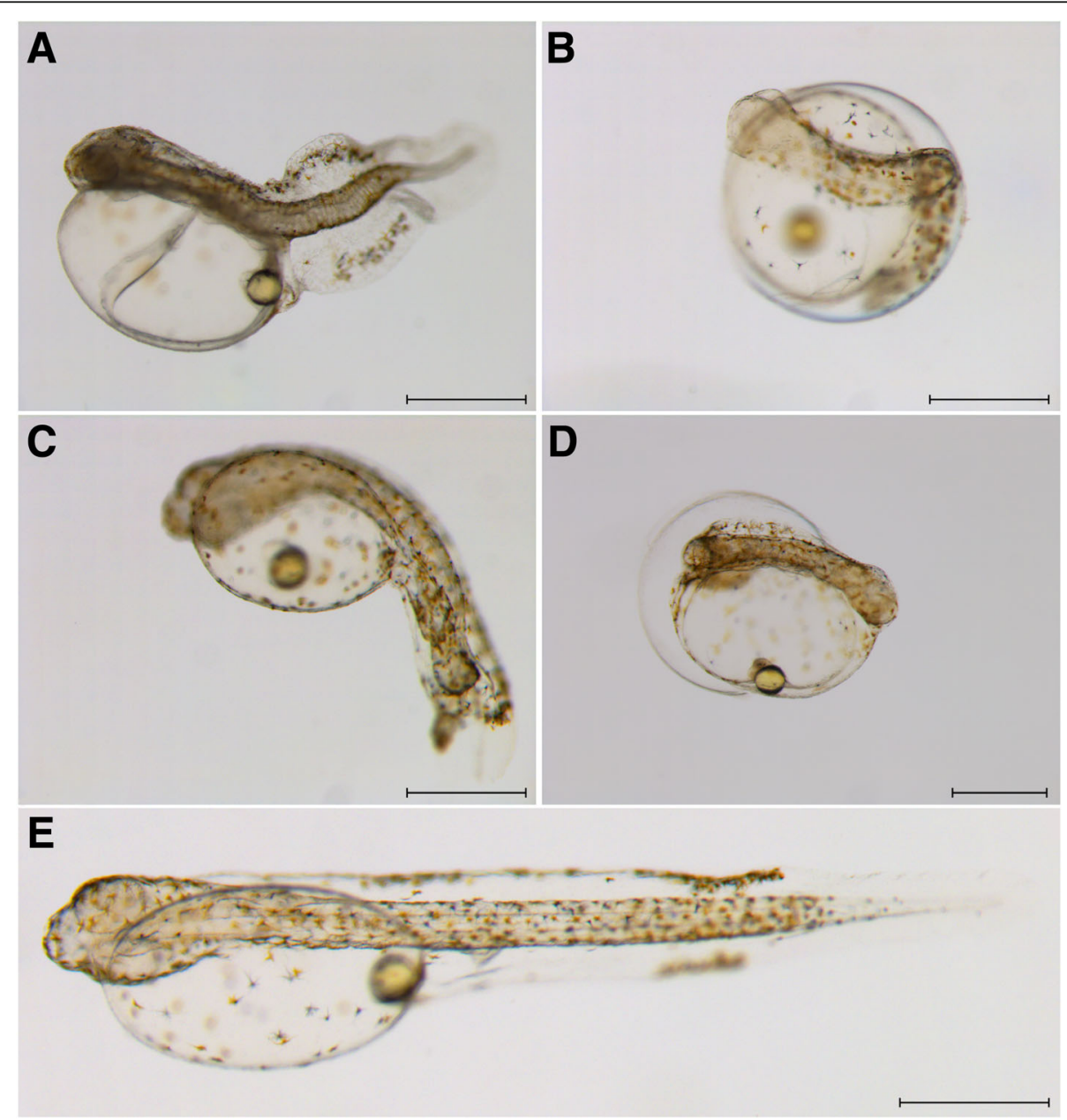

Fig. 2 Types of abnormal larvae that hatched from ARTP-treated eggs in Japanese flounder, Paralichthys olivaceus. a Abnormal larva with short tail trunk and large cardiocoelom; (b) abnormal larva with camptocormia at the middle of the trunk; (c) abnormal larva with tail folding; (d) abnormal larva with shortened trunk; (e) normal larva from the control group. Bar indicates $500 \mu \mathrm{m}$ 


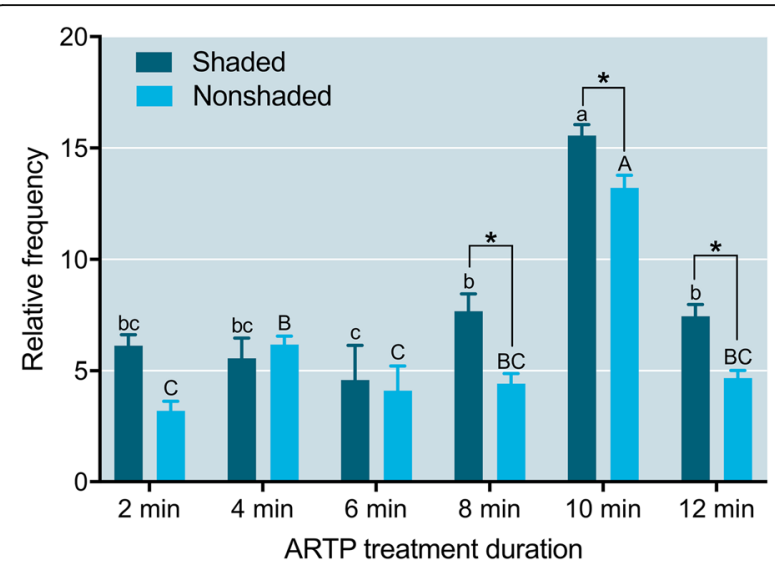

Fig. 3 Relative abnormal rates of 1:40 diluted sperm (40X) that underwent different ARTP treatment durations and shaded or nonshaded incubation before fertilizing eggs in Japanese flounder, Paralichthys olivaceus. Different lowercase letters indicate significant differences among ARTP treatment durations (shaded after treatment), and different capital letters indicate significant differences among ARTP treatment durations (nonshaded after treatment), as determined by oneway ANOVA and LSD multiple comparisons $(P<0.05)$. Asterisk indicates significant difference between the shaded and nonshaded groups as determined by paired t-test $(P<0.05)$

shaded treatment was significantly higher than that after the nonshaded treatment $(P<0.05)$ in the 8,10 , and 12 min ARTP irradiation groups.

For 1:6 diluted sperm (6X), the differences of relative abnormal rate in groups that were shaded after ARTP treatment were not significant $(P>0.05)$. Among the nonshaded groups, the relative abnormal rate of the $10 \mathrm{~min}$ ARTP treatment group was significantly higher than those of the 4 and 12 min groups $(P<0.05)$. The differences between shaded and nonshaded in each ARTP treatment group were not significant (Fig. 4).

Comparing the $40 \mathrm{X}$ and $6 \mathrm{X}$ diluted sperm after the shaded treatment, the relative abnormal rates of the 40X diluted sperm were significantly higher than those of the $6 \mathrm{X}$ diluted sperm in the 10 and $12 \mathrm{~min}$ ARTP treatment groups (Fig. 4). In addition, after the nonshaded treatment, significant differences were found in the 4 and $10 \mathrm{~min}$ ARTP treatment groups, in which the 40X diluted sperm had higher relative abnormal rates than those of the $6 \mathrm{X}$ diluted sperm (Fig. 5).

Overall, 40X dilution and a time period of $10 \mathrm{~min}$ ARTP treatment are optimal for Japanese flounder sperm. Exposure of the sperm to visible light could hinder the effect of ARTP treatment to the sperms, and darkness is preferred.

\section{Sperm quality detection after ARTP treatment}

Three types of fluorescence staining patterns were observed for the ARTP-treated and control sperm. Sperm with active mitochondria emitted green fluorescence, dead sperm emitted red fluorescence, and sperm with damaged plasma

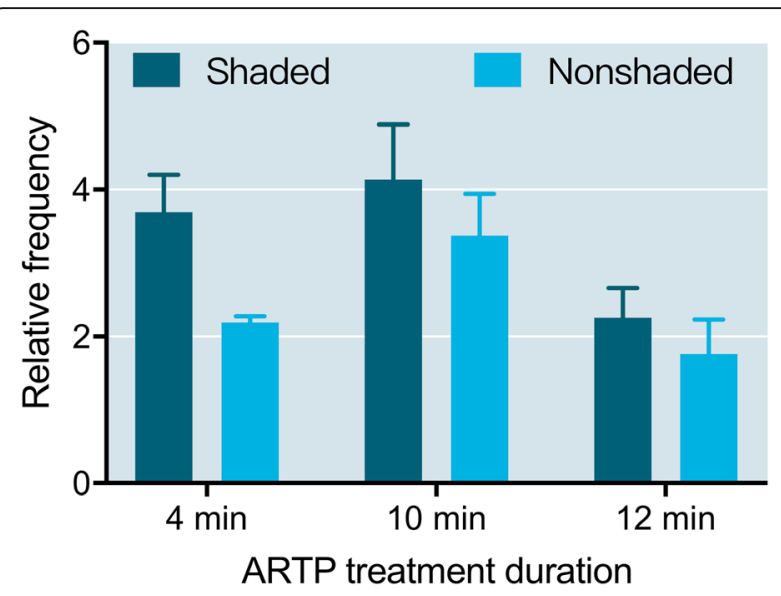

Fig. 4 Relative abnormal rates of 1:6 diluted sperm (6X) that underwent different ARTP treatment durations and shaded or nonshaded incubation before fertilizing eggs in Japanese flounder, Paralichthys olivaceus. Different lowercase letters indicate significant differences among ARTP treatment durations (shaded after treatment), and different capital letters indicate significant differences among ARTP treatment durations (nonshaded after treatment), as determined by one-way ANOVA and LSD multiple comparisons $(P<0.05)$

lemma and undamaged mitochondria emitted green-red fluorescence (Fig. 6). For sperm that were shaded after the ARTP treatment, the frequency of the green fluorescence type (ratio of green fluorescence type to total sperm) in the 2 min ARTP treatment group was not different from that in the control $(P>0.05)$; while from 2 to $10 \mathrm{~min}$ ARTP treatment, the frequency was decreased, but it increased again in the 12 min treatment group. For the red fluorescence type, all the ARTP-treated groups had higher frequencies than that of the control $(P<0.05)$, and the $12 \mathrm{~min}$ treatment group showed the highest frequency of $54.31 \pm$ $2.29 \%$. For the green-red fluorescence type, the frequencies of the 4 to $12 \mathrm{~min}$ treatment groups were significantly different from that of the control $(P<0.05)$, and the highest frequency of $67.31 \pm 1.27 \%$ was found in the $10 \mathrm{~min}$ treatment group (Fig. 7a). The frequency-change trends of different fluorescence types in nonshaded sperm were similar to those in shaded sperm (Fig. 7b).

Comparing the shaded and nonshaded treatments, except in the $12 \mathrm{~min}$ group, the groups (ARTP treatment for 2 to $10 \mathrm{~min})$ were significantly different $(P<0.05)$ in terms of frequency of green fluorescence type (Fig. 8a). Only the 2 min ARTP treatment group was significantly different $(P<0.05)$ in frequency of red fluorescence type (Fig. 8b). The 4 to 10 min ARTP groups were significantly different $(P<0.05)$ in frequency of green-red fluorescence type (Fig. 8c).

\section{Morphological characteristics}

Each 180 individuals from ARTP treatment and control groups were measured for body weight, total length, head 
A

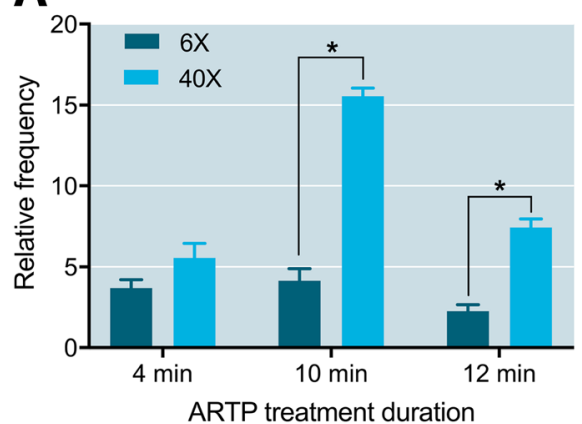

B

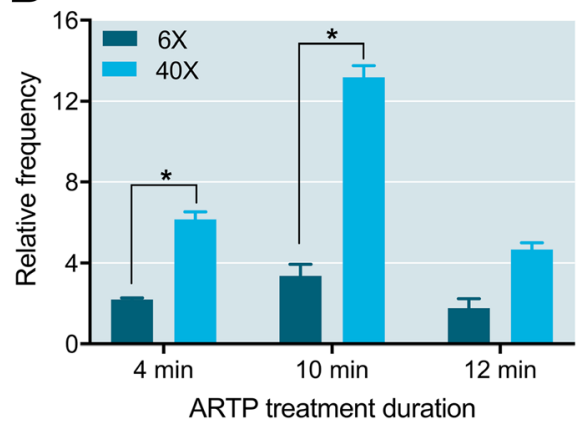

Fig. 5 Relative abnormal rates of 1:6 diluted sperm (6X) and 1:40 diluted sperm (40X) diluted sperm that underwent shaded or nonshaded incubation after ARTP treatment in Japanese flounder, Paralichthys olivaceus. a Shaded; (b) nonshaded. Asterisk indicates a significant difference as determined by paired t-test $(P<0.05)$

length, body height and caudal peduncle length at day 90 after hatch. Among all the traits measured, the total length, head length and caudal peduncle length were significantly different $(P<0.05)$ between the ARTP-treated group and control group. The differences in body weight and body height between the groups were not significant $(P>0.05)$ (Table 1). While the maximum value of each trait in the ARTP group was higher than that in the control group, and the minimum values in the ARTP group were lower than those in the control group. Except for the caudal peduncle length trait, the ARTP-treated group had higher CVs, and many morphological differences between individuals were present within the ARTP-treated group (Table 1) (Fig. 9).

\section{Genome-wide analysis of ARTP mutant individuals}

In total, we obtained $69.25 \mathrm{~Gb}$ clean data from three controls and eight randomly selected ARTP-treated individuals, and the GC contents ranged from 41.42 to $42.10 \%$. All samples were of high quality (Q20 $\geq 94.90 \%$, Q30 $\geq 87.09 \%$ ) (Table 2). The average mapping rate of sample to the reference genome sequence was $96.22 \%$, and the average depth was 9.77X (Table 3).

Compared with the reference genome sequence, 3,089,328, 2,828,464 and 2,822,287 SNPs were detected in controls 1, 2 and 3. For the ARTP-treated individual $\mathrm{m} 1$ to $\mathrm{m} 8$, the detected SNP number ranged from $2,873,580$ to $3,068,638$ (Table 4). In the case of InDels, 482,567, 433,478, and 433,286 were detected in controls 1, 2 and 3, respectively, and 434,536 to 488,874 were detected in the ARTP-treated individuals $\mathrm{m} 1$ to $\mathrm{m} 8$ (Table 5).

Next, ARTP-treated individuals $\mathrm{m} 1-\mathrm{m} 8$ were compared with controls 1,2 and 3 to remove the shared SNPs and InDels. The results of this comparison showed that the SNP number of the ARTP-treated samples

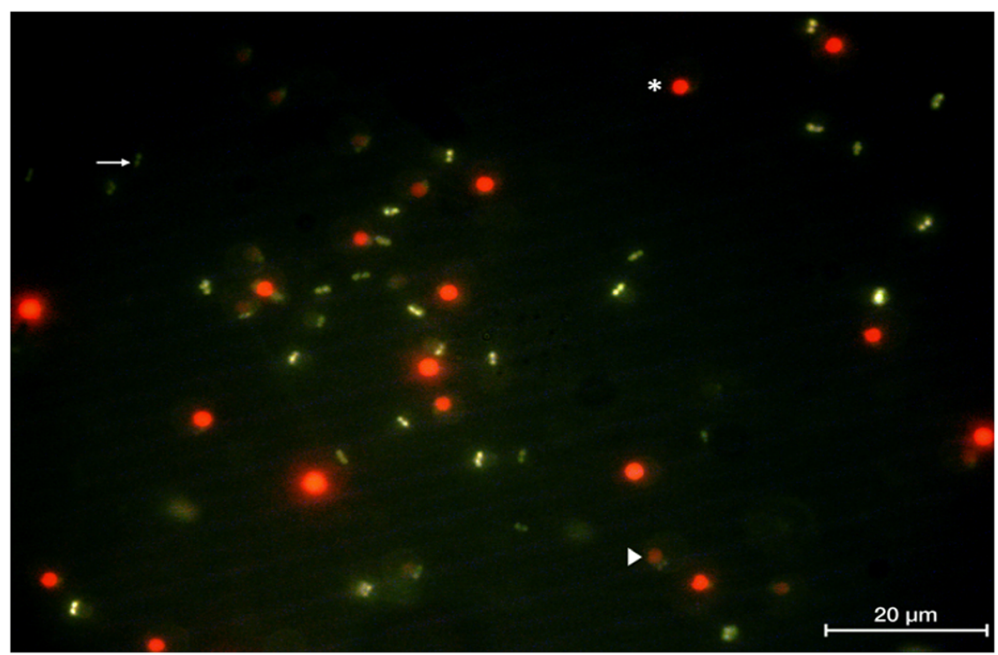

Fig. 6 Three types of fluorescence staining patterns for sperm treated by ARTP for 4 min and double-stained by Rh123 and PI in Japanese flounder, Paralichthys olivaceus. Arrow indicates mitochondrially active sperm; asterisk indicates dead sperm; triangle indicates sperm with damaged plasmalemma and undamaged mitochondria. Bar indicates $20 \mu \mathrm{m}$ 

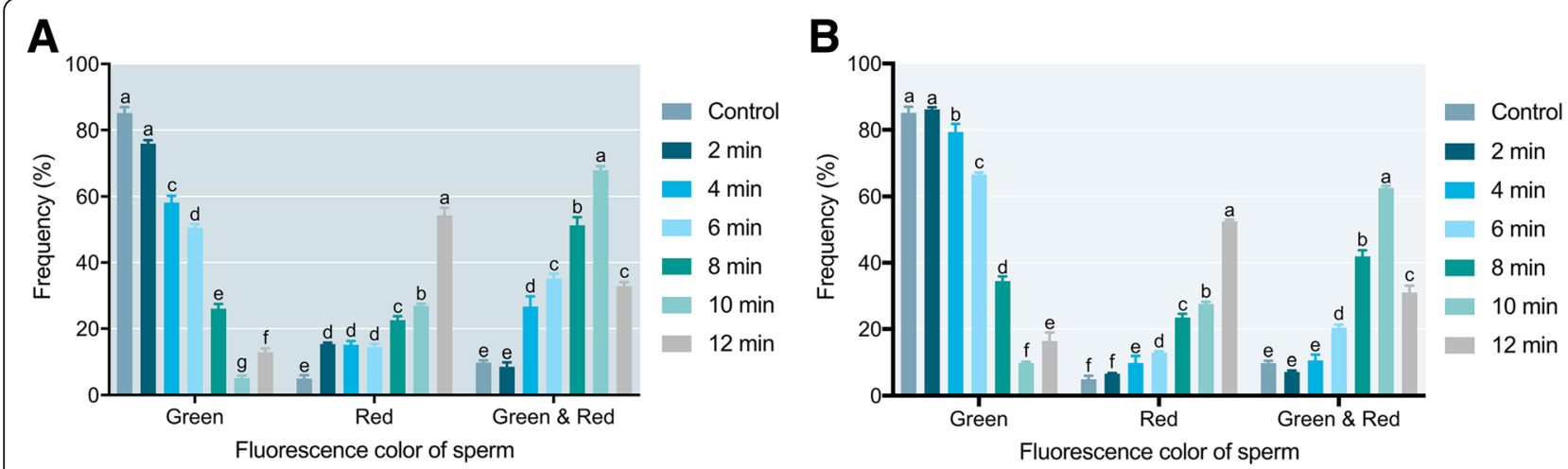

Fig. 7 Frequency of green-, red-, and green \& red-stained sperm after ARTP treatment for different durations in Japanese flounder, Paralichthys olivaceus . a Shaded; (b) nonshaded. Letters above columns indicate significant differences as determined by one-way ANOVA and LSD multiple comparisons $(P<0.05)$

ranged from 240,722 to 322,978 , and the InDel number ranged from 82,149 to 86,798 (Table 6). Comparing individual samples, the number of SNPs shared by sample pairs ranged from 57,561 ( $\mathrm{m} 3 \mathrm{vs} \mathrm{m} 6)$ to 72,473 ( $\mathrm{m} 5$ vs m8) (Fig. 10), and the shared InDel number ranged from 22,383 (m3 vs $\mathrm{m} 2$ ) to 23,716 (Fig. 11)

In the ARTP-treated samples, a mean percentage of $45.96 \%$ of SNPs were located in intergenes, while 43.60 and
3.07\% were in introns and exons. SNP types such as upstream, downstream, upstream/downstream and splicing that we classified as 'others' accounted for7.37\% (Fig. 12). The majority of InDel types in the ARTP-treated samples were intergenic and intronic, which had mean percentages of 45.70 and $44.99 \%$, respectively, followed by upstream (4.28\%) and downstream (3.66\%) types. Other 1.37\% InDel types included upstream/downstream, frameshift deletion,

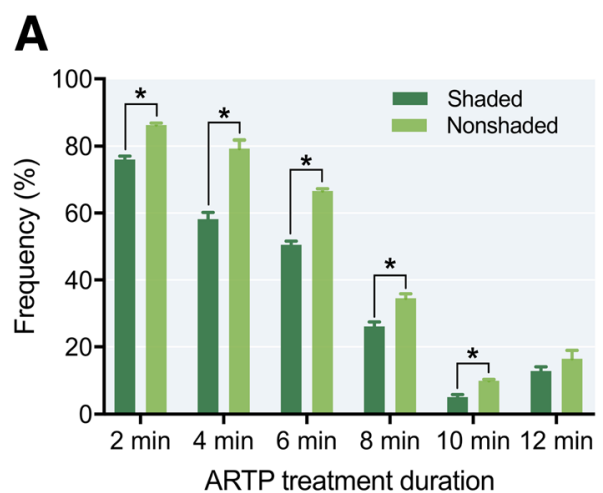

B

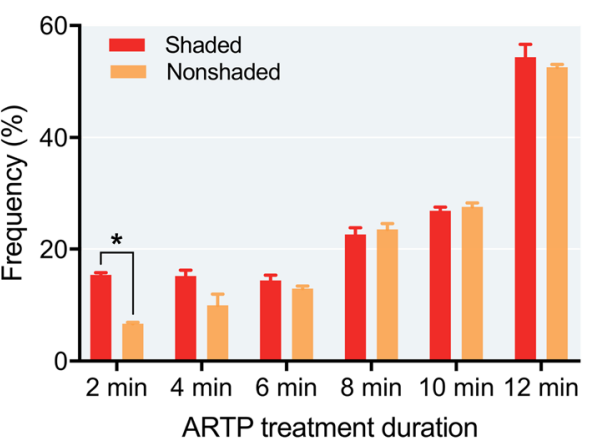

C

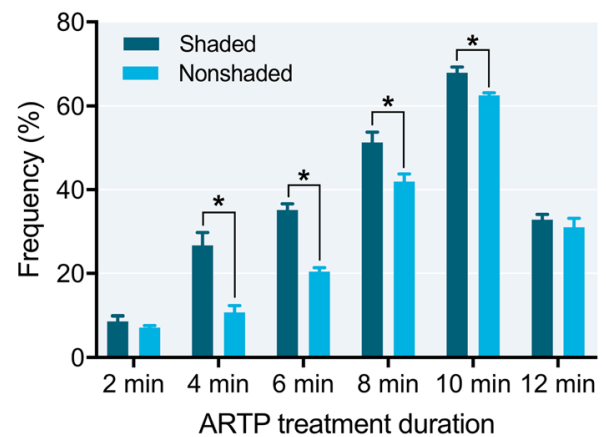

Fig. 8 Frequency of green-, red-, and green \& red-stained sperm that underwent shaded or nonshaded incubation after ARTP treatment in Japanese flounder, Paralichthys olivaceus. a Green-stained sperm; (b) red-stained sperm; (c) green \& red-stained sperm. Asterisk indicates a significant difference as determined by paired t-test $(P<0.05)$ 
Table 1 Morphological traits of ARTP treated and control Japanese flounder, Paralichthys olivaceus

\begin{tabular}{|c|c|c|c|c|c|c|c|c|}
\hline & \multicolumn{2}{|l|}{ Mean \pm SD } & \multicolumn{2}{|l|}{ CV (\%) } & \multicolumn{2}{|l|}{ Max } & \multicolumn{2}{|l|}{ Min } \\
\hline & ARTP group & Control group & ARTP group & Control group & ARTP group & Control group & ARTP group & Control group \\
\hline Body weight (g) & $8.82 \pm 3.22^{\mathrm{a}}$ & $9.02 \pm 2.64^{\mathrm{a}}$ & 36.53 & 29.08 & 32.10 & 15.30 & 3.20 & 4.40 \\
\hline Total length $(\mathrm{cm})$ & $8.65 \pm 1.10^{\mathrm{a}}$ & $8.28 \pm 0.96^{\mathrm{b}}$ & 12.74 & 11.63 & 13.23 & 10.35 & 5.29 & 6.27 \\
\hline Head length $(\mathrm{cm})$ & $2.08 \pm 0.29^{a}$ & $1.98 \pm 0.26^{b}$ & 13.83 & 13.04 & 3.23 & 2.48 & 1.30 & 1.34 \\
\hline Body height $(\mathrm{cm})$ & $3.92 \pm 0.56^{\mathrm{a}}$ & $3.84 \pm 0.45^{\mathrm{a}}$ & 14.32 & 11.77 & 6.21 & 4.90 & 2.32 & 2.94 \\
\hline Caudal peduncle length $(\mathrm{cm})$ & $1.89 \pm 0.25^{\mathrm{a}}$ & $1.71 \pm 0.24^{b}$ & 13.09 & 14.11 & 2.55 & 2.16 & 1.00 & 1.27 \\
\hline
\end{tabular}

Note: different superscript letters between columns indicates significant differences as determined by paired t-test $(P<0.05)$

frameshift insertion, frameshift substitution, nonframe shift deletion, nonframe shift insertion, nonframe shift substitution, splicing, stop gain SNV, and stop loss SNV (Fig. 13).

\section{Functional clustering of the mutant genes}

In total, SNPs and InDels were located in 17,394 18,457 and 12,907 13,333 genes, respectively (Fig. 14). GO annotation was performed and plotted by WEGO for gene function clustering (Figs. 15 and 16). The results indicated that SNPs and InDels were distributed among different gene ontologies. In the cellular component ontology, the GO terms cell and cell part contained the majority of the mutant genes, with 34.3\% SNPs on average and 34.7\% InDels. GO terms associated with the extracellular region, such as extracellular matrix and extracellular space, had relatively lower numbers of the mutant genes. In the molecular function ontology, binding and catalytic activity contained higher mutation rates. Mutations in the binding term were composed of $34.4 \%$ SNPs and $35.2 \%$ InDels, while the catalytic activity term was composed of $21.3 \%$ SNPs and $21.6 \%$ InDels. For the biological process ontology, cellular process, metabolic process and biological regulation had high gene mutation rates. Mutations in the cellular process term were composed of $41.6 \%$ SNPs and $42.3 \%$ InDels. Metabolic process contained $28.3 \%$ SNPs and $28.2 \%$. Biological regulation included 25.7\% SNPs and 26.5\% InDels.

\section{Mutant genes pertaining to the growth and immune pathways}

We selected five genes that were related to growth (mstn, myod) and immune regulation (tp53, mhclzaa, mhc2dab) to investigate the distribution of SNPs. In the eight ARTP-treated individuals, 5 to 33 SNPs were then detected (Table 7). Five SNPs of $t p 53$ gene, and one SNP of $m s t n$ gene that detected in ARTP treated samples were selected for confirmation by using Sanger sequencing. The result indicated that these SNPs were only detected in ARTP treated samples, but not in controls, which was identical with result of whole genome sequencing (Table 8). Interestingly, a high percentage of SNPs were located in the exon and intron regions of tp53, mhc1zaa and mhc2dab. Such SNPs may be beneficial for the further molecular breeding,

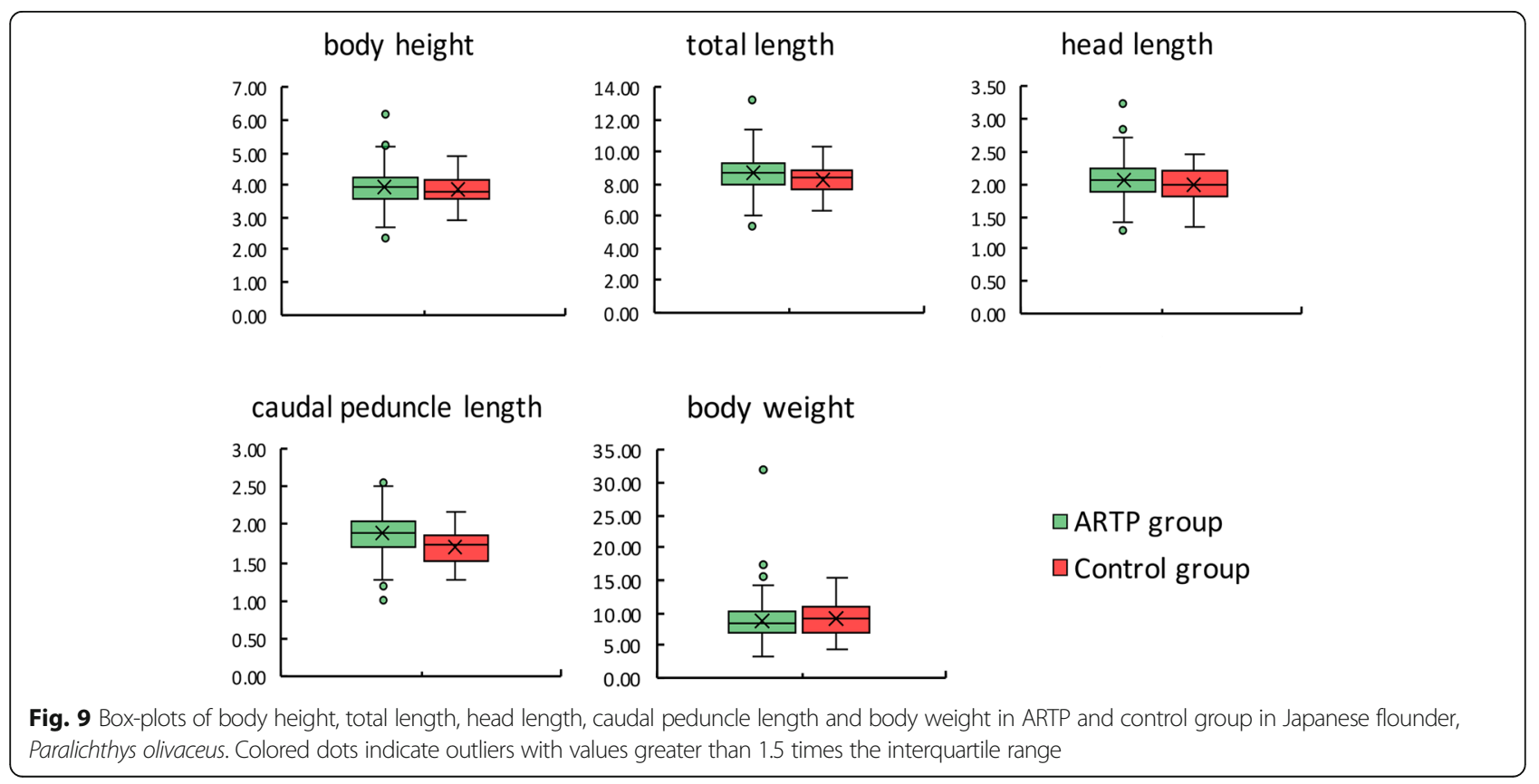


Table 2 Genome sequencing data and quality of each sample

\begin{tabular}{llllllll}
\hline Sample & Raw Base $(\mathrm{bp})$ & Clean Base(bp) & Effective Rate(\%) & Error Rate(\%) & Q20(\%) & Q30(\%) & GC Content(\%) \\
\hline c1 & $7,062,951,300$ & $7,049,850,900$ & 99.81 & 0.04 & 96.20 & 90.28 & 41.89 \\
c2 & $5,863,885,800$ & $5,846,086,200$ & 99.70 & 0.04 & 96.45 & 90.91 & 41.99 \\
c3 & $5,782,930,200$ & $5,770,443,900$ & 99.78 & 0.04 & 96.59 & 91.13 & 41.95 \\
m1 & $6,310,089,300$ & $6,294,106,500$ & 99.75 & 0.04 & 96.46 & 90.88 & 41.99 \\
m2 & $6,472,890,300$ & $6,459,912,300$ & 99.80 & 0.04 & 96.59 & 91.12 & 41.64 \\
m3 & $6,625,437,000$ & $6,594,946,500$ & 99.54 & 0.04 & 96.21 & 90.34 & 42.05 \\
m4 & $6,345,791,100$ & $6,330,096,600$ & 99.75 & 0.04 & 96.30 & 90.50 & 41.97 \\
m5 & $6,039,080,700$ & $6,017,527,500$ & 99.64 & 0.05 & 94.90 & 87.09 & 42.02 \\
m6 & $6,755,125,800$ & $6,715,168,200$ & 99.41 & 0.04 & 96.50 & 94.72 & 42.10 \\
m7 & $6,306,369,000$ & $6,287,940,000$ & 99.71 & 0.04 & 96.52 & 90.95 & 41.94 \\
m8 & $5,902,783,200$ & $5,886,753,900$ & 99.73 & 0.04 & 97.32 & 93.14 & 41.42 \\
\hline
\end{tabular}

because it is possible that the SNPs will accelerate the selection of disease-resistant new varieties.

\section{Discussion}

ARTP is a novel, efficient, safe and environment-friendly mutagenesis tool with a higher mutation rate than those of traditional mutagens [17]. Although ARTP mutagenesis has been widely applied to microbial mutation breeding and proved its effectiveness, its application in aquaculture species has not been reported so far. In this study, we applied ARTP to mutation breeding of Japanese flounder for the first time by optimizing ARTP mutation conditions. The success and feature of the ARTP mutagenesis for the fish was confirmed by SNP and InDel calling at the genome level.

In microbial mutation breeding, lethality and positive mutation rate were used as indexes for determining the ARTP treatment conditions [31]. However, in our study, unlike the microbial mutagenesis, due to the difficulty of determining the positive fish mutation rate (because long period of the growth is required), we defined the abnormal rate as the index of ARTP treatment to the fish eggs and sperm.

Under the same ARTP power and working gas flow rate, ARTP treatment time is equivalent to the mutation dosage, and the optimal treatment time in this study was significantly longer than that for microbes. The reason might be the differences in sizes and structures between Japanese flounder eggs and microbes. The eggs of Japanese flounder are approximately $1 \mathrm{~mm}$ in diameter, but for most microbes, the diameter is measured in $\mu \mathrm{m}$. For example, Crypthecodinium cohnii is $25 \mu \mathrm{m}$ in long diameter [32], which is almost 40 times smaller than that of the Japanese flounder eggs. Thus, the relatively large size of the egg might require a higher ARTP plasma irradiation dosage, indicating that under a fixed input power of ARTP, a longer irradiation duration is required. For sperm, although the diameter of the head is approximately $1.5 \mu \mathrm{m}$, the high level of chromatin condensation might reduce the DNA-damage effect of ARTP treatment and give rise to the longer irradiation duration.

Table 3 Summary of assembly results

\begin{tabular}{|c|c|c|c|c|c|c|}
\hline Sample & Total reads & Mapped reads & Mapping rate (\%) & Average depth $(X)$ & $\begin{array}{l}\text { Coverage at } \\
\text { least } 1 \times(\%)\end{array}$ & $\begin{array}{l}\text { Coverage at } \\
\text { least } 4 \mathrm{X}(\%)\end{array}$ \\
\hline$\overline{c 1}$ & $46,999,006$ & $45,302,172$ & 96.39 & 10.54 & 99.33 & 95.68 \\
\hline c2 & $38,973,908$ & $37,467,504$ & 96.13 & 9.15 & 99.19 & 91.90 \\
\hline c3 & $38,469,626$ & $37,028,773$ & 96.25 & 9.11 & 99.18 & 91.75 \\
\hline $\mathrm{m} 1$ & $41,960,710$ & $40,458,673$ & 96.42 & 9.68 & 99.25 & 93.58 \\
\hline $\mathrm{m} 2$ & $43,066,082$ & $41,487,247$ & 96.33 & 9.89 & 99.29 & 94.35 \\
\hline m3 & $43,966,310$ & $42,412,162$ & 96.47 & 10.12 & 99.30 & 94.68 \\
\hline $\mathrm{m} 4$ & $42,200,644$ & $40,611,165$ & 96.23 & 9.76 & 99.27 & 93.83 \\
\hline m5 & $40,116,850$ & $38,536,371$ & 96.06 & 9.43 & 99.21 & 92.64 \\
\hline m6 & $44,767,788$ & $42,971,134$ & 95.99 & 10.86 & 99.36 & 96.06 \\
\hline m7 & $41,919,600$ & $40,377,059$ & 96.32 & 9.69 & 99.25 & 93.50 \\
\hline m8 & $39,245,026$ & $37,616,558$ & 95.85 & 9.20 & 99.21 & 92.34 \\
\hline
\end{tabular}


Table 4 SNP information for control and ARTP treated samples after calling

\begin{tabular}{|c|c|c|c|c|c|c|c|c|c|c|c|}
\hline Sample & Upstream & Exonic & Intronic & Splicing & Downstream & upstream/downstream & Intergenic & Total & ts & tv & $\mathrm{ts} / \mathrm{tv}$ \\
\hline$\overline{c 1}$ & 116,469 & 116,181 & $1,356,072$ & 272 & 101,018 & 5849 & $1,393,467$ & $3,089,328$ & $1,676,361$ & $1,412,967$ & 1.186 \\
\hline$c 2$ & 106,347 & 109,337 & $1,241,373$ & 250 & 92,833 & 5258 & $1,273,066$ & $2,828,464$ & $1,537,682$ & $1,290,782$ & 1.191 \\
\hline c3 & 105,941 & 108,654 & $1,239,371$ & 262 & 92,870 & 5236 & $1,269,953$ & $2,822,287$ & $1,534,177$ & $1,288,110$ & 1.191 \\
\hline m1 & 109,996 & 112,412 & $1,288,306$ & 263 & 95,991 & 5487 & $1,321,804$ & $2,934,259$ & $1,595,108$ & $1,339,151$ & 1.191 \\
\hline $\mathrm{m} 2$ & 112,947 & 111,782 & $1,314,387$ & 259 & 98,438 & 5714 & $1,351,103$ & $2,994,630$ & $1,623,581$ & $1,371,049$ & 1.184 \\
\hline m3 & 113,352 & 114,531 & $1,317,274$ & 272 & 98,624 & 5595 & $1,352,071$ & $3,001,719$ & $1,630,355$ & $1,371,364$ & 1.188 \\
\hline $\mathrm{m} 4$ & 111,372 & 112,731 & $1,296,977$ & 270 & 96,508 & 5583 & $1,326,500$ & $2,949,941$ & $1,601,682$ & $1,348,259$ & 1.187 \\
\hline m5 & 107,632 & 109,741 & $1,263,174$ & 254 & 94,376 & 5404 & 1,292,999 & $2,873,580$ & $1,560,292$ & $1,313,288$ & 1.188 \\
\hline m6 & 115,586 & 116,261 & $1,347,778$ & 276 & 100,946 & 5744 & $1,382,047$ & $3,068,638$ & $1,666,239$ & $1,402,399$ & 1.188 \\
\hline m7 & 109,894 & 111,811 & $1,286,623$ & 269 & 96,192 & 5416 & $1,320,482$ & $2,930,687$ & $1,592,922$ & $1,337,765$ & 1.19 \\
\hline m8 & 108,839 & 105,835 & $1,265,898$ & 243 & 95,682 & 5439 & $1,301,310$ & $2,883,246$ & $1,562,074$ & $1,321,172$ & 1.182 \\
\hline
\end{tabular}

We also interestingly found that the nonshade treatment after 8 to12 min ARTP treatments of 40X diluted sperm could significantly increase the normal rate of hatched larvae. Effect of light on hatching process of sperm has little been known. The nonshade effect mentioned above might be explained by nucleotide excision repair (NER) or photoreactivation repair (PER) theory. These two mechanisms are two major repair pathways for UV-induced photolesions [33]. In fish, NER or PER have been studied in vivo [34] and in vitro [33]. In rainbow trout (Oncorhynchus mykiss) cell lines, PER repair much faster the UV lesions than NER [33]. NER or PER could also repair UV irradiated sperm [35]. Preventing UV irradiated sperm from visible light is crucial for induction success rate in artificial gynogenesis. However, ARTP has very low UV level, and whether NER or PER could be related to repair of the ARTP treated sperm is not clear, and needs further studies.

In this study, we used next-generation whole-genome sequencing technology to analyze the genetic mutations in ARTP-treated individuals. This study represents the first time that whole-genome sequencing technology has been used for ARTP-induced mutation of fish. Three female parents were from a homozygous clonal family with a genetic similarity of 1.00 and a homozygosity of 1.00 [27]. And a male doubled haploid with homozygosity of 1.00 was used as male parent [28]. The offspring obtained by normal fertilization of these parents were heterozygous clones, and the genetic similarity between the offspring was 1.00 [36]. We compared each ARTP treated sample $\mathrm{m} 1-\mathrm{m} 8$ with $\mathrm{c} 1$ first, then compared the results with $\mathrm{c} 2$, and then compared the results with $\mathrm{c} 3$. The final results were used for the next analysis. This not only removed the shared SNPs of $\mathrm{m} 1 \sim \mathrm{m} 8$ to each control, but also removed the natural mutation occurred, because in nature, the mutation rate per generation was low, for mouse, SNP mutation rate was $4 \times$ $10^{-9}$, and $3 \times 10^{-8}$ for human [37]. For Japanese flounder, the estimate natural mutation of SNP per generation is about 546 [the genome size of Japanese flounder is $5.46 \times 10^{8}(546 \mathrm{Mb})$ [29], and mutation rate is set as $1 \times$ $10^{-6}$ ]. Such a low number of natural mutation could not affect the calculation of ARTP mutagenesis rate.

We found that the mutation rate in terms of SNPs and InDels was $0.064 \%$ on average at the genome level. Gene

Table 5 InDel information for control and ARTP treated samples after calling

\begin{tabular}{|c|c|c|c|c|c|c|c|c|}
\hline Sample & Upstream & Exonic & Intronic & Splicing & Downstream & Upstream/Downstream & Intergenic & Total \\
\hline$\overline{c 1}$ & 19,889 & 3412 & 220,932 & 182 & 18,222 & 1003 & 218,927 & 482,567 \\
\hline$c 2$ & 17,988 & 3139 & 198,478 & 162 & 16,294 & 884 & 196,533 & 433,478 \\
\hline c3 & 17,785 & 3140 & 198,681 & 159 & 16,398 & 898 & 196,225 & 433,286 \\
\hline m1 & 18,655 & 3251 & 207,611 & 179 & 17,114 & 944 & 205,527 & 453,281 \\
\hline $\mathrm{m} 2$ & 19,241 & 3251 & 212,754 & 165 & 17,651 & 979 & 211,069 & 465,110 \\
\hline m3 & 19,398 & 3406 & 214,410 & 181 & 17,663 & 971 & 211,730 & 467,759 \\
\hline $\mathrm{m} 4$ & 18,900 & 3281 & 208,851 & 170 & 17,254 & 916 & 206,160 & 455,532 \\
\hline m5 & 17,825 & 3188 & 198,936 & 162 & 16,571 & 892 & 196,962 & 434,536 \\
\hline m6 & 20,213 & 3487 & 224,314 & 186 & 18,366 & 1006 & 221,302 & 488,874 \\
\hline m7 & 18,525 & 3237 & 207,038 & 174 & 17,040 & 929 & 204,741 & 451,684 \\
\hline m8 & 18,423 & 2985 & 203,099 & 156 & 16,988 & 941 & 201,253 & 443,845 \\
\hline
\end{tabular}


Table 6 SNP and InDel number of ARTP treated samples after removing shared types with controls

\begin{tabular}{lll}
\hline Sample & No. of SNP & No. of InDel \\
\hline m1 & 288,011 & 83,400 \\
m2 & 271,922 & 82,149 \\
m3 & 269,932 & 82,623 \\
m4 & 285,635 & 83,359 \\
m5 & 322,978 & 86,798 \\
m6 & 240,722 & 82,545 \\
m7 & 289,809 & 83,822 \\
m8 & 298,869 & 86,224 \\
\hline
\end{tabular}

mutation rate is one of the main points of interest in studies of artificial mutation induction. In ENU-induced mutation of zebrafish [38] and $\gamma$-radiation/ENU-induced mutation of medaka [10, 39], the mutation rate was calculated using albino mutants, which carry mutations in the tyrosinase gene and are readily visible due to their red eyes. However, albino mutations are found in only a few species, not in all fish species in nature [1]. With the development of molecular technology, the mutation rate can be calculated as the frequency of mutated base pairs to the total length of specific genes using technology such as direct resequencing or high-resolution melting analysis [1, 4-6]. We used whole-genome sequencing with an average depth of $9.77 \mathrm{X}$, and such a large scale increases the possibility for discovering more mutation loci. Although ARTP radiation is a physical process, the genes in the genome seemed to have an even opportunity to be mutated. However, we found in our study that different genes had different mutation rates after ARTP radiation. So, calculation of mutation rate based on a single gene or several genes could increase large errors, and the whole-genome scale of measure is a more reliable way to detect the effects of chemical or physical mutagenesis on gene mutation rate.

Among the mutations, SNPs were in the majority, indicating that point mutations were the main type of variation induced by ARTP treatment. Similar results were also found in rice (Oryza sativa L. ssp. indica) mutations induced by $\gamma$-radiation [40] and in ENU-induced mutations in medaka [4], fugu [1], and zebrafish [5]. In $\gamma$ and $X$ ray irradiation, other types of mutations were also observed. X ray irradiation could cause mutations such as single-nucleotide variants, InDels as well as copy number variants (CNVs) in mice [41]. CNVs and presence/absence variations were also detected in the genome of $\gamma$ irradiated rice [40]. And in medaka, deletion of genome sequence could be induced by $\gamma$-radiation [10]. However, whether mutations like CNV etc. occurred in ARTP treated individuals are not clear, and need further study. Furthermore, WEGO clustering of mutant genes showed equal

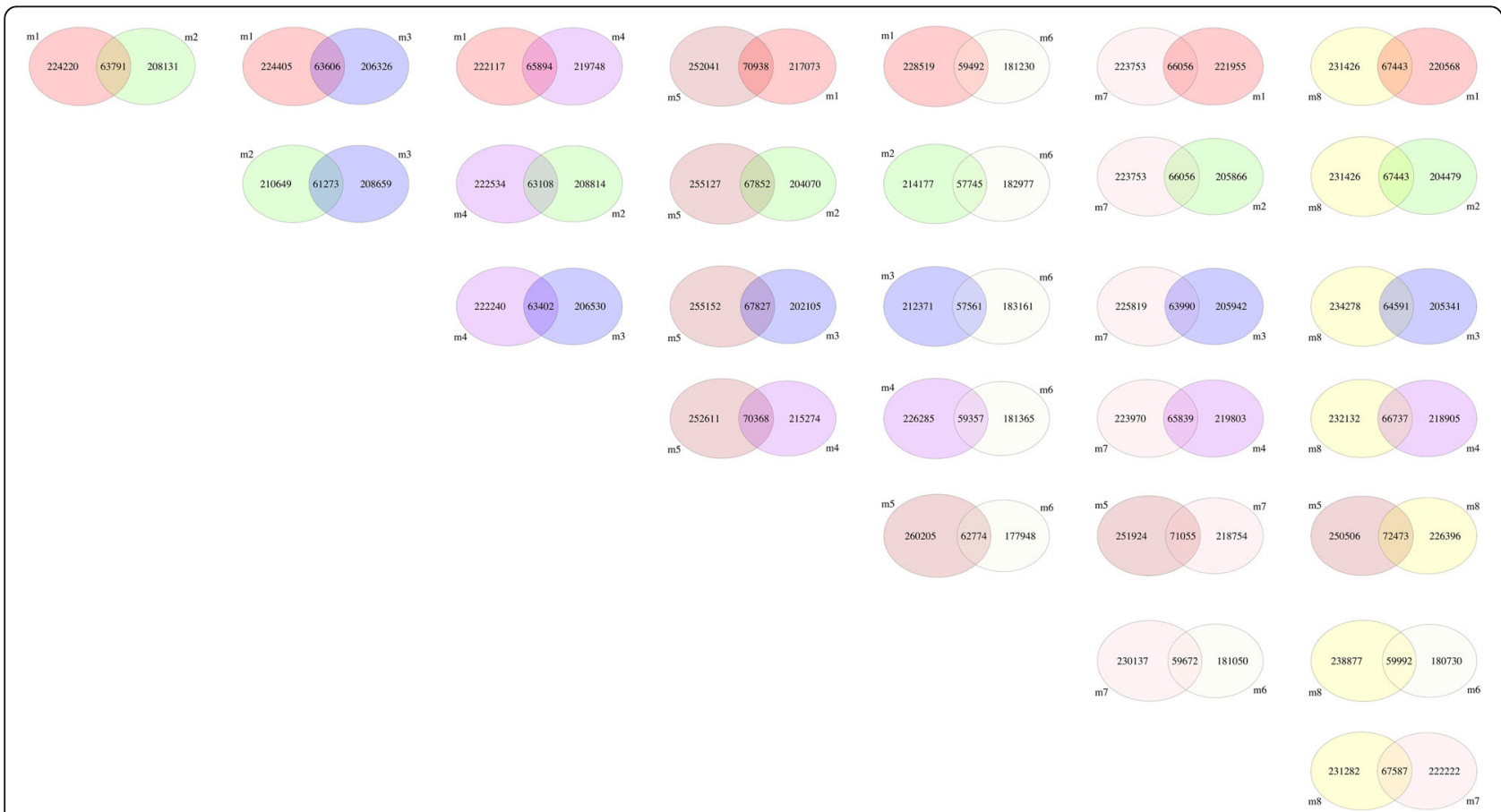

Fig. 10 SNP comparison among individuals of ARTP-treated Japanese flounder, Paralichthys olivaceus. The difference of SNP for each two individuals was represented using single Venn diagram. For example, individual $\mathrm{m} 1$ compared with $\mathrm{m} 2,224,220$ was the number of unique SNP of $m 1$ when compared with $m 2,208,131$ was the number of unique SNP of $m 2$ when compared with $m 1$, and 63,791 was the SNP number that shared by $m 1$ and $m 2$ 


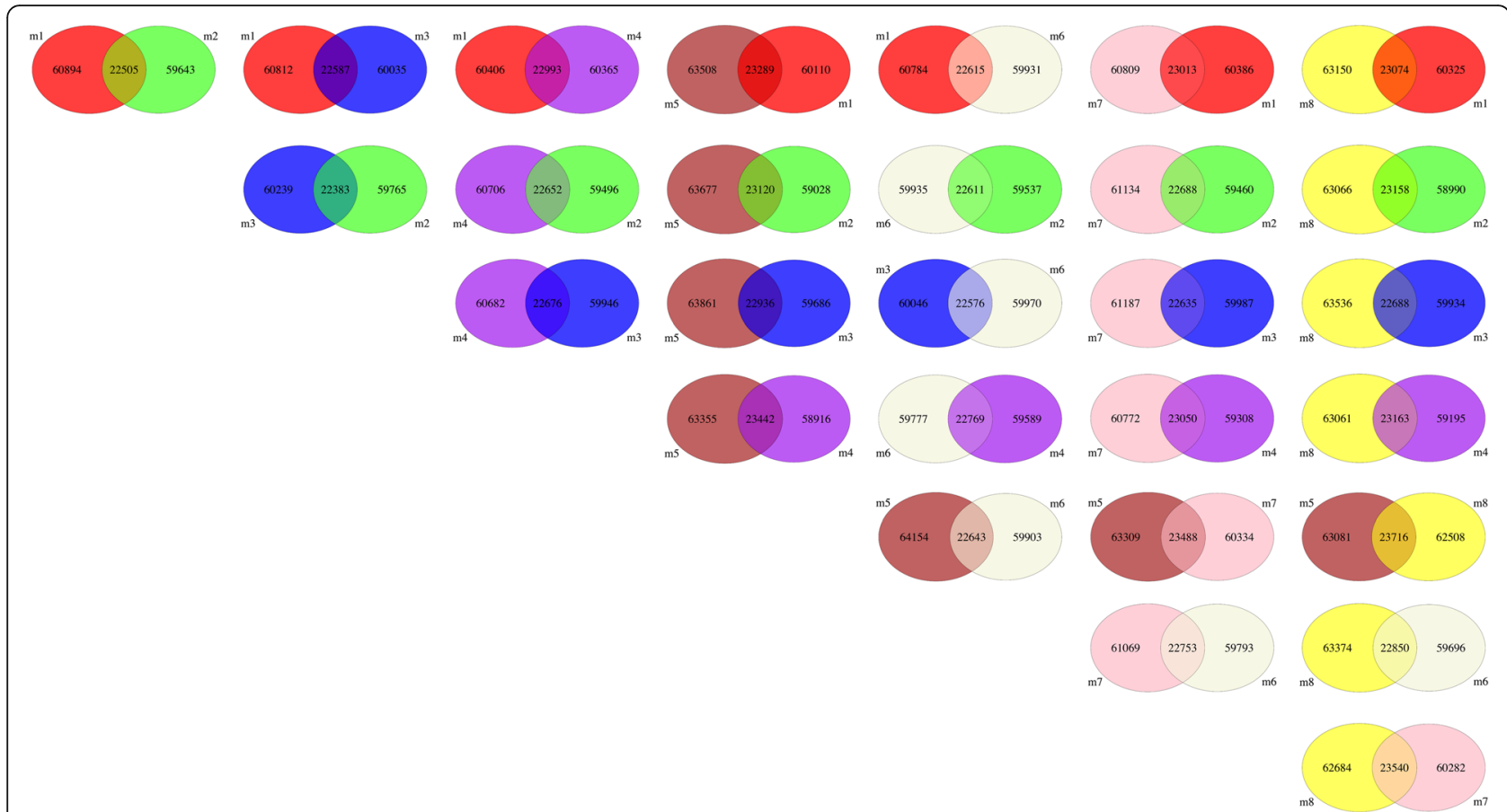

Fig. 11 InDel comparison among individuals of ARTP-treated Japanese flounder, Paralichthys olivaceus. The difference of InDel for each two individuals was represented using single Venn diagram. For example, individual $\mathrm{m} 1$ compared with $\mathrm{m} 2,60,894$ was the number of unique InDel of $\mathrm{m} 1$ when compared with $\mathrm{m} 2,59,643$ was the number of unique InDel of $\mathrm{m} 2$ when compared with $\mathrm{m} 1$, and 22,505 was the InDel number that shared by $\mathrm{m} 1$ and $\mathrm{m} 2$

distribution of different gene ontologies between SNPs and InDels, as well as among the individuals. This result indicated that ARTP-treated individuals share similar survival and distribution patterns in terms of gene ontology.

\section{Conclusions}

In conclusion, the ARTP mutagenesis method was established for breeding of Japanese flounder by optimizing the ARTP treatment time period and the genome mutation analysis of the mutated fish using whole-genome

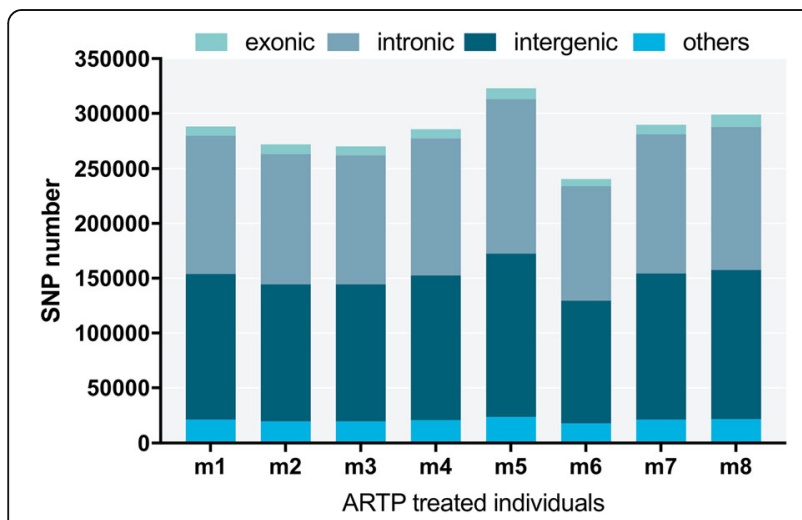

Fig. 12 Numbers of different types of SNP in individual ARTPtreated Japanese flounder, Paralichthys olivaceus sequencing. This is the first report that the novel ARTP mutagenesis is an applicable method for breeding of fish species. This approach may play a significant role in commercial breeding for selection of economically important traits that would benefit the aquaculture industry.

\section{Methods}

\section{Fish and gamete collection}

The experiment was performed at Beidaihe Central Experimental Station, Chinese Academy of Fishery Sciences. Mature female and male Japanese flounders were reared in the conditions used by Hou et al. (2016) [28]. A second-generation homozygous clone family 3165 [27] was used for egg collection, and eggs were manually stripped and collected with 1000-ml glass beakers. In total, three clonal females were used for egg collection. Sperm was collected with a 5 -ml syringe from one doubled haploid male by gentle pressure on the abdomen. The collected eggs and sperm were stored in darkness before use.

\section{Mutation by ARTP}

For mutation of the fertilized eggs, the sperm was diluted with Ringer's solution at a ratio of $1: 40 \mathrm{v} / \mathrm{v}$, added to eggs, mixed well and activated using $17^{\circ} \mathrm{C}$ filtered seawater. The fertilized eggs were incubated at $17^{\circ} \mathrm{C}$ until $60 \mathrm{~min}$ after fertilization and then treated with a 


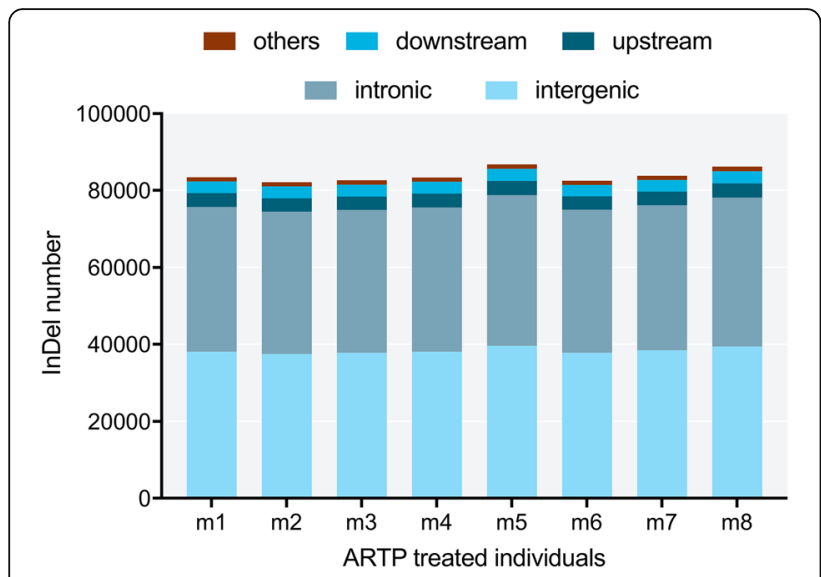

Fig. 13 Numbers of different types of InDels in individual ARTPtreated Japanese flounder, Paralichthys olivaceus

pure helium-based ARTP mutation machine (ARTP-A, TMAXTREE Biotechnology Co., Ltd., Luoyang, China). Approximately 1800 eggs at metaphase of first mitosis were placed on a glass Petri dish with $1 \mathrm{~mL}$ sea water. The dish was then exposed to the plasma, and the ARTP mutation system was operated with the following parameters: radio-frequency (RF) power input of $120 \mathrm{~W}$, helium gas flow rate of $10 \mathrm{~L} / \mathrm{min}$, treatment distance of 2 $\mathrm{mm}$, and treatment time period of $1.5,3,6,9,12,14,25$ and $30 \mathrm{~min}$. After the ARTP mutation treatment, eggs were transferred to a $17^{\circ} \mathrm{C}$ water bath until hatching.

For mutation using the sperm, $5 \mathrm{ml}$ of Ringer's solution-diluted sperm was placed on a glass Petri dish and treated by ARTP with operating parameters as follows: RF power input of $200 \mathrm{~W}$, helium gas flow rate of $10 \mathrm{~L} / \mathrm{min}$, treatment distance of $2 \mathrm{~mm}$, and treatment time period of $2,4,6,8,10$, and 12 min for 1:40 diluted sperm (40X) and 4 and $10 \mathrm{~min}$ for 1:6 diluted sperm (6X). After ARTP treatment, the sperm was shaded or unshaded from visible light and used to fertilize eggs within $5 \mathrm{~min}$. The fertilized eggs were transferred to a $17^{\circ} \mathrm{C}$ water bath until hatching.

\section{Fertilization, hatch and abnormal rates}

The fertilization, hatch and abnormal rates were calculated according to Hou et al. (2016) [28]. For mutation using sperm, the relative abnormal rate was calculated as the ratio of the abnormal rate in the ARTP treatment group to that in the control group.

\section{Fluorescence staining of ARTP-treated sperm}

Both the ARTP-treated and control sperm were doublestained with $10 \mu \mathrm{g} / \mathrm{ml} \mathrm{Rh} 123$ and PI for $10 \mathrm{~min}$ in darkness. For each group, $200 \mu \mathrm{l}$ of sperm was stained. After staining, $20 \mu \mathrm{l}$ of solution was placed on a slide and observed under a fluorescence microscope (Leica DM 4000B) with an excitation wavelength of $488 \mathrm{~nm}$. At least 3000 stained spermatozoa were observed for each group.

\section{Morphological characteristics of ARTP-treated individuals}

The ARTP-treated group (fertilized eggs with an ARTP treatment time of $25 \mathrm{~min}$ ) was cultured under the same conditions as the control group. From day 0 to day 60, the larvae were reared in a 3- $\mathrm{m}^{3}$ aquarium for each group with flow-through seawater. At day 61, the fish of each group were transferred to a $25-\mathrm{m}^{3}$ tank. At day 90, 180 individuals each from the ARTP and control groups were randomly selected and measured for body weight, total length, head length, body height and caudal peduncle length.

\section{Whole-genome sequencing}

At day 120 after hatching, eight individuals from the ARTP-treated group and three individuals from the control group were randomly selected, respectively, and the fin samples were cut. Genomic DNA was isolated from each fin sample using phenol-chloroform extraction [42]. Following quality assessment, the isolated genomic DNA was

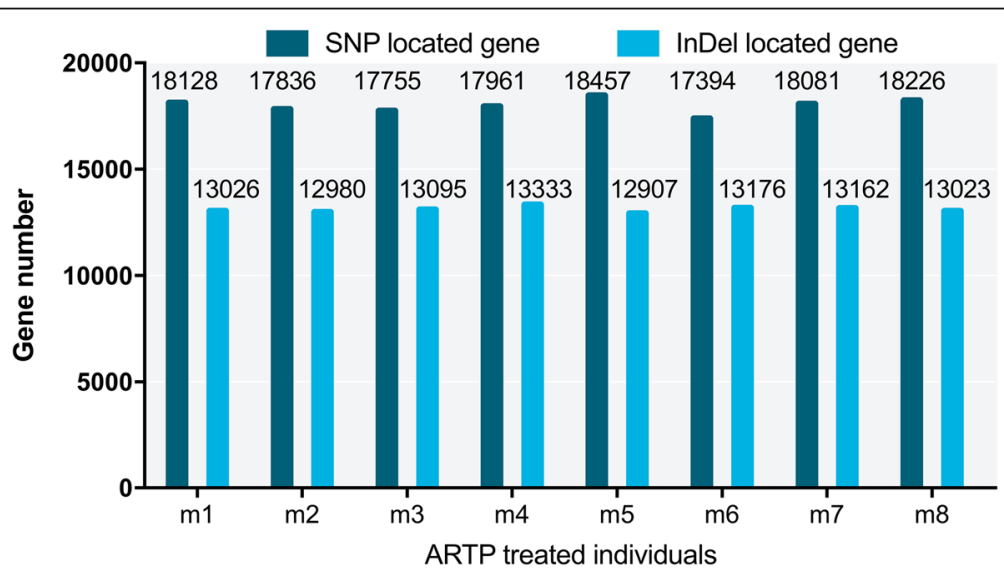

Fig. 14 SNP and Indel distribution in the genomes of individual Japanese flounder, Paralichthys olivaceus 


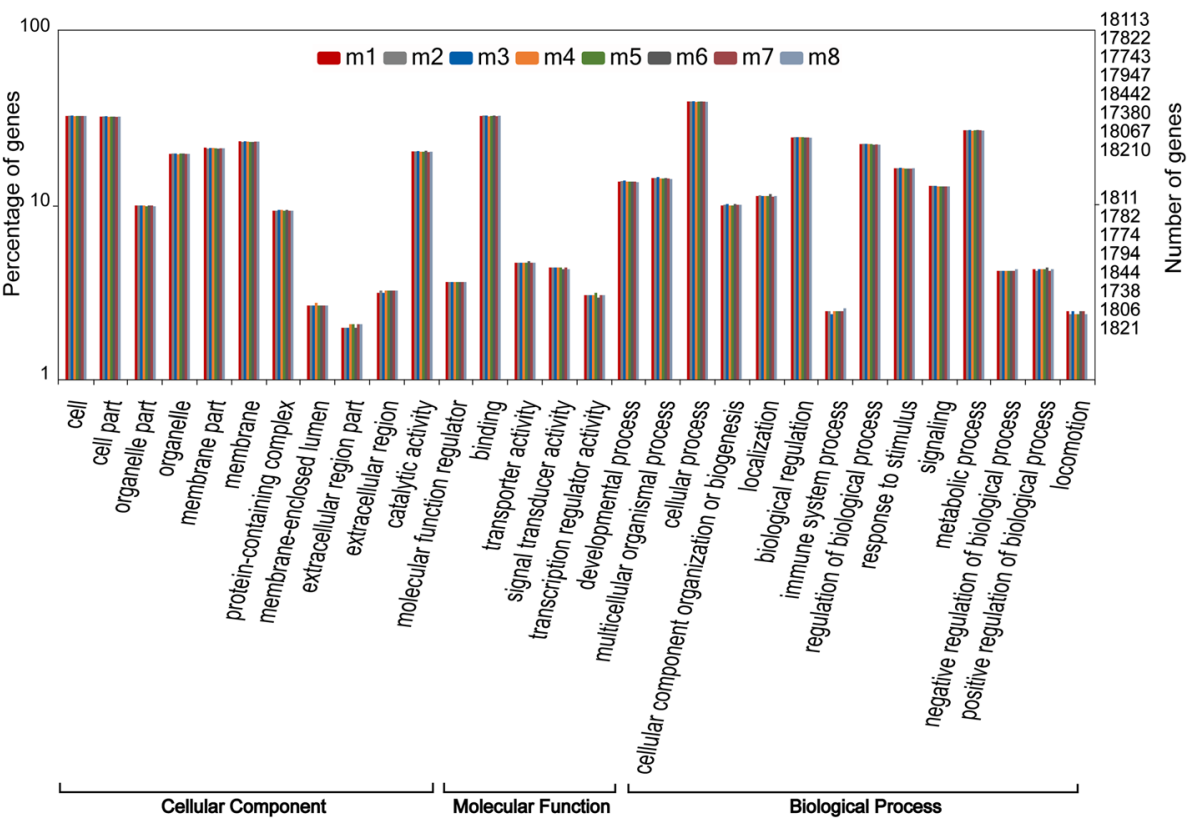

Fig. 15 WEGO clustering of genes with SNPS

randomly fragmented into $350 \mathrm{bp}$ by sonication. The fragmented DNA was then prepared for library construction using the TruSeq DNA Library Prep Kit HT (FC-121-2003, Illumina), and sequenced by Illumina NovaSeq 6000 .

\section{SNP and InDel detection}

Paired-end sequencing reads were mapped to the Japanese flounder reference genome [29] with BWA
[43] using default settings. SAMtools [44] software was used to filter the unmapped and nonunique reads (parameter: rmdup), and the duplicated reads were filtered with the PICARD package (http:// broadinstitute.github.io/picard). The raw SNP/InDel sets were first called by SAMtools with parameters as 'mpileup -m 2 -F 0.002 -d 1000', and then, these called sets were further filtered using the following

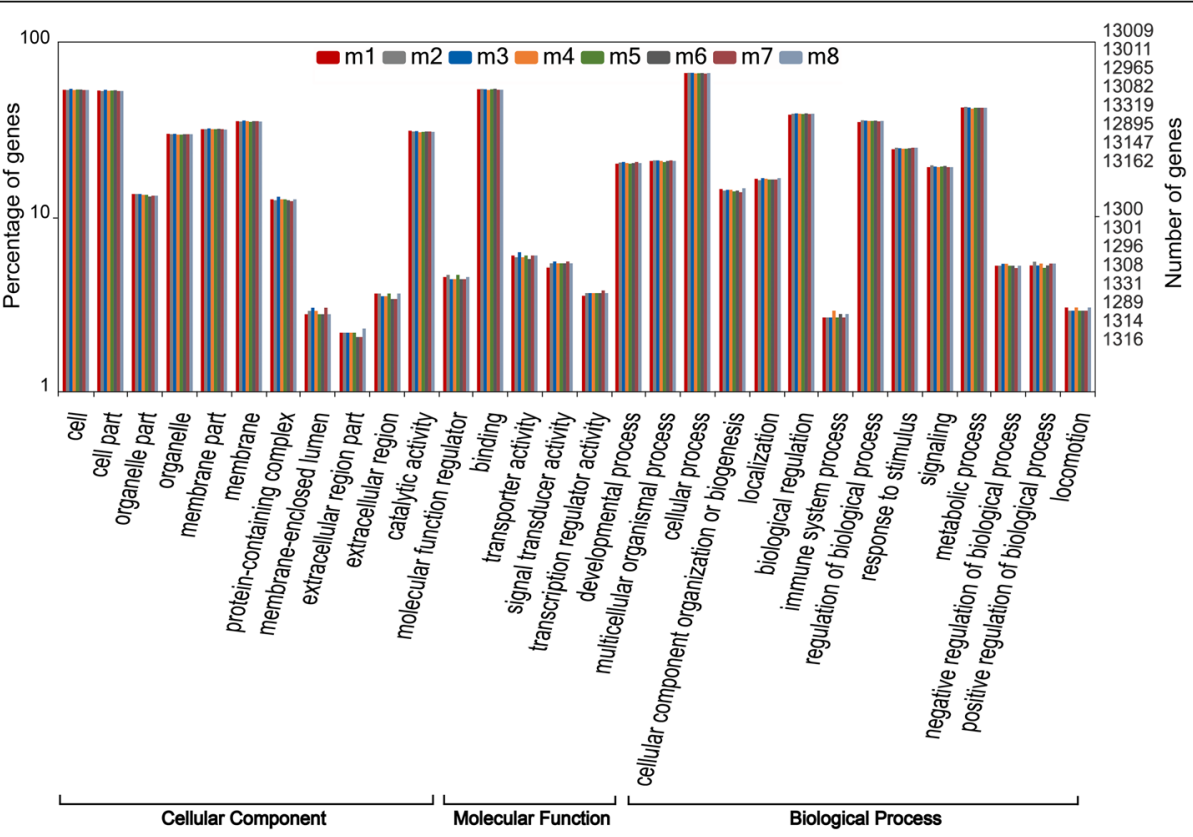

Fig. 16 WEGO clustering of genes with InDels 
Table 7 Selected gene mutations in ARTP treated samples

\begin{tabular}{|c|c|c|c|c|c|c|c|c|c|}
\hline Gene & Chromosome & Length (bp) & Group & Total No. of SNP & Exonic & Intronic & Downstream & Intergenic & Upstream \\
\hline \multirow[t]{2}{*}{ mstn } & 15 & 11,730 & ARTP treated & 11 & 1 & 1 & 1 & 8 & 1 \\
\hline & & & Control & 3 & / & / & 1 & 2 & 1 \\
\hline \multirow[t]{2}{*}{ myod } & 7 & 68,283 & ARTP treated & 19 & / & 6 & 5 & 4 & 4 \\
\hline & & & Control & 3 & / & 1 & / & 2 & \\
\hline \multirow[t]{2}{*}{ tp53 } & 9 & 35,221 & ARTP treated & 33 & 5 & 28 & / & / & / \\
\hline & & & Control & 14 & 7 & 7 & & & \\
\hline \multirow[t]{2}{*}{ mhcizaa } & 22 & 10,720 & ARTP treated & 13 & / & 9 & / & 4 & / \\
\hline & & & Control & 2 & / & / & / & 1 & 1 \\
\hline \multirow[t]{2}{*}{$m h c 2 d a b$} & 6 & 9736 & ARTP treated & 5 & / & 5 & / & / & / \\
\hline & & & Control & 0 & / & / & / & / & / \\
\hline
\end{tabular}

criteria: mapping quality $>20$, and the depth of the variate position $>4$. After calling, the $\mathrm{SNPs} / \mathrm{InDels}$ were annotated to the Japanese flounder reference genome [29] using the package ANNOVAR [45]. We compared each ARTP treated sample m1-m8 with C1 first, then compared the results with c2, and then compared the results with $\mathrm{c} 3$. The final results were used for the next analysis. This removed the shared SNPs or InDels of $\mathrm{m} 1 \sim \mathrm{m} 8$ to each control. Gene Ontology (GO) clustering analysis of genes that contained SNPs or InDels was performed by WEGO 2.0 [46].

\section{PCR and sanger sequencing}

To verify the SNPs that detected by whole-genome sequencing, five SNPs of tp53 gene, and one SNP of mstn gene were selected. DNA from eight individuals of the ARTP-treated group and three individuals of the control group that used for whole-genome sequencing were used here for PCR amplification. The PCR cocktail was $15 \mu \mathrm{L}$ in volume, containing $1.5 \mu \mathrm{L}$ of $10 \times$ buffer, $1.5 \mu \mathrm{L}$ of $\mathrm{Mg}^{2+}$ $(25 \mathrm{mmol} / \mu \mathrm{L}), 0.25 \mu \mathrm{L}$ of dNTPs $(10 \mathrm{mmol} / \mu \mathrm{L}), 0.15 \mu \mathrm{L}$ of each primer $(10 \mathrm{pmol} / \mu \mathrm{L}), 0.2 \mu \mathrm{L}$ of Taq DNA polymerase $(5 \mathrm{u} / \mu \mathrm{L}), 1 \mu \mathrm{L}$ of DNA (30 50 ng), and $9.5 \mu \mathrm{L}$ of $\mathrm{ddH}_{2} \mathrm{O}$. PCR thermal cycles comprised of one cycle of pre-denature $\left(95^{\circ} \mathrm{C}\right.$ for $3 \mathrm{~min}$ ), followed by 35 cycles of amplification ( 94 ${ }^{\circ} \mathrm{C}$ for $15 \mathrm{~s}, 55^{\circ} \mathrm{C}$ for $15 \mathrm{~s}, 72^{\circ} \mathrm{C}$ for $30 \mathrm{~s}$ ), and a final extension step $\left(72{ }^{\circ} \mathrm{C}\right.$ for $\left.3 \mathrm{~min}\right)$. Cloning of PCR products and Sanger sequencing were performed according to Jiang et al. (2011) [6].

\section{Statistical analysis}

All ARTP treatment experiments were performed in triplicate, and the data are given in the format mean $\pm \mathrm{SD}$ (standard deviation). The coefficient of variation $(\mathrm{CV})$ was calculated as the ratio of SD to mean. The data for the optimization of ARTP treatment duration were analyzed by a one-way analysis of variance (ANOVA) followed by LSD

Table 8 SNP verified by Sanger sequencing

\begin{tabular}{|c|c|c|c|c|c|c|}
\hline Gene & Locus & Primers 5'-3' & Size (bp) & SNP type & $\begin{array}{l}\text { Detected in ARTP } \\
\text { treated sample }\end{array}$ & $\begin{array}{l}\text { Detected } \\
\text { in control }\end{array}$ \\
\hline \multirow[t]{10}{*}{$\operatorname{tp53}$} & $9,685,724$ & F: TGAAGAGCATAGCCAGGAG & 228 & $A>T$ & $\mathrm{~m} 8$ & / \\
\hline & & R: ACCCTGATTCTITAGGCCT & & & & \\
\hline & $9,704,973$ & F: TCAGGTATGGCTTCCTCAC & 236 & $A>G$ & m5, m6, m8 & / \\
\hline & & R: AAACAAGACTTACTCGGGAG & & & & \\
\hline & $9,705,000$ & F: TCACTCAGGGGAACATGT & 192 & $T>A$ & $m 5, m 6, m 7, m 8$ & / \\
\hline & & R: TCAGGATGGTGAGGATCTG & & & & \\
\hline & $9,705,895$ & F: TTCCTGTGAGTAATGATGCAGT & 226 & $\mathrm{~T}>\mathrm{C}$ & m5, m6, m7, m8 & / \\
\hline & & R: ACATTTGGAATTGATTGCAAAGT & & & & \\
\hline & $9,712,498$ & F: CCCATTTGTTCAGAACCGC & 164 & $G>A$ & $m 5, m 6, m 7, m 8$ & / \\
\hline & & R: TCCAGTGAGAACGATTGCC & & & & \\
\hline \multirow[t]{2}{*}{ mstn } & $6,396,324$ & F: TCTCAGACCGTGATGTIIT & 228 & $\mathrm{C}>\mathrm{T}$ & $\mathrm{m} 2, \mathrm{~m} 4, \mathrm{~m} 7$ & / \\
\hline & & R: ATTCCTGGTGGTCTGTG & & & & \\
\hline
\end{tabular}


multiple comparisons $(P<0.05)$. Paired t-tests were performed to compare the morphological characteristics between the ARTP-treated group and control group, as well as to compare different dilutions or shaded/nonshaded treatments in the sperm. For all statistical analyses, R software was used [47].

\section{Abbreviations}

ARTP: Atmosphere and room temperature plasma; AVOVA: One-way analysis of variance; CNVs: Copy number variants; CV: Coefficient of variation; ENU: Nethyl-N-nitrosourea; GO: Gene ontology; InDel: Insertion-deletion; LSD: Leastsignificant difference; NER: Nucleotide excision repair; PER: Photoreactivation repair; RF APGD: Radio-frequency atmospheric-pressure glow discharge; RF: Radio-frequency; SD: Standard deviation; SNP: Single nucleotide polymorphism; UV: Ultraviolet

\section{Acknowledgements}

We thank Mr. Ma Xiaobing for his assistant in analysis whole genome sequencing data.

\section{Funding}

This work was financially supported by the Nature Science Foundation of Hebe (C2018107006); China Agriculture Research System (CARS-47); Applied National Science and Technology Support Program in China (2012BAD26B01); National Natural Science Foundation of China (No. 31602128); and Natural Science Foundation of Shanghai (No. 16ZR1415300). These funding bodies had no role in the design of the study, collection, analysis, and interpretation of data, or in writing the manuscript.

\section{Availability of data and materials}

All data generated or analyzed during this study are included in this published article. Clean data of 11 genomes re-sequenced in Japanese flounder are available from the NCBI short read archive (SRA) associated with BioProject: PRJNA490566.

\section{Authors' contributions}

$H J, X X$, and WY designed the study. HJ, ZX, WG, SZ performed the experiments. DW, ZY, SF and YQ had contributions in fish culturing. WL provided the ARTP machine. HJ wrote the manuscript. All authors read and approved the final manuscript.

\section{Ethics approval and consent to participate}

All animal experiments were approved by the Animal Care and Use Committees of the Beidaihe Central Experiment Station, Chinese Academy of Fishery Sciences.

\section{Consent for publication}

Not applicable.

\section{Competing interests}

The authors declare that they have no competing interests.

\section{Publisher's Note}

Springer Nature remains neutral with regard to jurisdictional claims in published maps and institutional affiliations.

\section{Author details}

${ }^{1}$ Key Laboratory of Aquatic Genomics, Ministry of Agriculture, Beijing, China. ${ }^{2}$ Beidaihe Central Experiment Station, Chinese Academy of Fishery Sciences, Qinhuangdao, China. ${ }^{3}$ TmaxTree Biotechnology Company, Luoyang, China. ${ }^{4}$ Key Laboratory for Industrial Biocatalysis, Ministry of Education, Department of Chemical Engineering, Tsinghua University, Beijing, China. ${ }^{5}$ Center for Synthetic and Systems Biology, Tsinghua University, Beijing, China.

Received: 16 October 2018 Accepted: 9 April 2019

Published online: 29 April 2019

\section{References}

1. Kuroyanagi M, Katayama T, Imai T, Yamamoto Y, Chisada S-I, Yoshiura Y, Ushijima T, Matsushita T, Fujita M, Nozawa A, Suzuki Y, Kikuchi K. New approach for fish breeding by chemical mutagenesis: establishment of TILLING method in fugu (Takifugu rubripes) with ENU mutagenesis. BMC Genomics. 2013;14:786.

2. Knapik EW. ENU mutagenesis in zebrafish-from genes to complex diseases. Mamm Genome. 2014;11:511-9.

3. Mullins MC, Hammerschmidt M, Haffter P, Nüsslein-Volhard C. Large-scale mutagenesis in the zebrafish: in search of genes controlling development in a vertebrate. Curr Biol. 1994;4:189-202.

4. Taniguchi Y, Takeda S, Furutani-Seiki M, Kamei Y, Todo T, Sasado T, Deguchi T, Kondoh H, Mudde J, Yamazoe M, Hidaka M, Mitani H, Toyoda A, Sakaki Y, Plsaterk RHA, Cuppen E. Generation of medaka gene knockout models by target-selected mutagenesis. Genome Biol. 2006;7:R116.

5. Wienholds E, Schulte-Merker S, Walderich B, Plasterk RHA. Target-selected inactivation of the zebrafish rag1 gene. Science. 2002;297:99-102.

6. Jiang $X Y$, Sun $C F$, Zhang QG, Zou SM. ENU-induced mutagenesis in grass carp (Ctenopharyngodon idellus) by treating mature sperm. PLoS One. 2011; 6:e26475.

7. Driever W, Solnica-Krezel L, Schier AF, Neuhauss SC, Malicki J, Stemple DL, Stainier DYR, Zwartkruis F, Rangini AZ, Belak J, Boggs C. A genetic screen for mutations affecting embryogenesis in zebrafish. Development. 1996;123:37-46.

8. Loosli F, Köster RW, Carl M, Kühnlein R, Henrich T, Mücke M, Krone A, Wittbrodt J. A genetic screen for mutations affecting embryonic development in medaka fish (Oryzias latipes). Mech Dev. 2000;97:133-9.

9. Kodym A, Afza R. Physical and chemical mutagenesis. Methods Mol Biol. 2003;236:189-204.

10. Shima A, Shimada A. Development of a possible nonmammalian test system for radiation-induced germ-cell mutagenesis using a fish, the Japanese medaka (Oryzias latipes). Proc Natl Acad Sci. 1991;88:2545-9.

11. Li G, Li HP, Wang LY, Wang S, Zhao HX, Sun WT, Xing XH, Bao CY. Genetic effects of radio-frequency, atmospheric-pressure glow discharges with helium. Appl Phys Lett. 2008;92:221504

12. Li HP, Wang LY, Li G, Jin LH, Le PS, Zhao HX, Xing XH, Bao CY. Manipulation of lipase activity by the helium radio-frequency, atmospheric-pressure glow discharge plasma jet. Plasma Process Polym. 2011;8:224-9.

13. Li HP, Wang ZB, Ge N, Le PS, Wu H, Lu Y, Wang LY, Zhang C, Bao CY, Xing $\mathrm{XH}$. Studies on the physical characteristics of the radio-frequency atmospheric-pressure glow discharge plasmas for the genome mutation of Methylosinus trichosporium. IEEE T Plasma Sci. 2012:40:2853-60.

14. Zhang $X$, Zhang XF, Li HP, Wang LY, Zhang C, Xing XH, Bao CY. Atmospheric and room temperature plasma (ARTP) as a new powerful mutagenesis tool. Appl Microbiol Biot. 2014;98:5387-96.

15. Zhang X, Zhang C, Zhou QQ, Zhang XF, Wang LY, Chang HB, Li HP, Oda Y, Xing $\mathrm{XH}$. Quantitative evaluation of DNA damage and mutation rate by atmospheric and room-temperature plasma (ARTP) and conventional mutagenesis. Appl Microbiol Biot. 2015;99:5639-46.

16. Wang LY. Studies on the mechanisms and applications of the atmospheric room temperature plasmas acting on the microbes. Ph. D. Thesis, Tsinghua University. 2009; 1-157. (In Chinese with English abstract).

17. Ottenheim C, Nawrath M, Wu JC. Microbial mutagenesis by atmospheric and room-temperature plasma (ARTP): the latest development. Bioresour Bioprocess. 2018:5:464.

18. Wang $L Y$, Huang $Z L, L i G$, Zhao HX, Xing XH, Sun WT, Li HP, Guo ZX, Bao CY. Novel mutation breeding method for Streptomyces avermitilis using an atmospheric pressure glow discharge plasma. J Appl Microbiol. 2010;108: 851-8.

19. Cui LY, Wang SS, Guan CG, Liang WF, Xue ZL, Zhang C, Xing XH. Breeding of methanol-tolerant Methylobacterium extorquens AM1 by atmospheric and room temperature plasma mutagenesis combined with adaptive laboratory evolution. Biotechnol J. 2018:13:e1700679.

20. Lu Y, Wang LY, Ma K, Li G, Zhang C, Zhao HX, Lai QH, Li HP, Xing XH. Characteristics of hydrogen production of an Enterobacter aerogenes mutant generated by a new atmospheric and room temperature plasma (ARTP). Biochem Eng J. 2011;55:17-22.

21. Wang $Q$, Feng $L R$, Wei L, Li HG, Wang L, Zhou Y, Yu XB. Mutation breeding of lycopene-producing strain Blakeslea trispora by a novel atmospheric and room temperature plasma (ARTP). Appl Biochem Biotechnol. 2014;174:452-60.

22. Shi F, Tan J, Chu J, Wang Y, Zhuang Y, Zhang S. A qualitative and quantitative high-throughput assay for screening of gluconate high-yield strains by Aspergillus niger. J Microbiol Meth. 2015;109:134-9.

23. Liu B, Sun Z, Ma X, Yang B, Jiang Y, Wei D, Chen F. Mutation breeding of extracellular polysaccharide-producing microalga Crypthecodinium cohnii by 
a novel mutagenesis with atmospheric and room temperature plasma. Int J Mol Sci. 2015;16:8201-12.

24. Tan Y, Fang M, Jin L, Zhang C, Li HP, Xing XH. Culture characteristics of the atmospheric and room temperature plasma-mutated Spirulina platensis mutants in $\mathrm{CO}_{2}$ aeration culture system for biomass production. J Biosci Bioeng. 2015;120:438-43.

25. Fang M, Jin L, Zhang C, Tan Y, Jiang P, Ge N, Li HP, Xing XH. Rapid mutation of Spirulina platensis by a new mutagenesis system of atmospheric and room temperature plasmas (ARTP) and generation of a mutant library with diverse phenotypes. PLoS One. 2013;8:e77046.

26. Yamamoto E. Studies on sex-manipulation and production of cloned populations in hirame, Paralichthys olivaceus (Temminck et Schlegel). Aquaculture. 1999;173:235-46.

27. Hou JL, Wang GX, Zhang XY, Wang YF, Sun ZH, Si F, Jiang XF, Liu HJ. Production and verification of a 2 nd generation clonal group of Japanese flounder, Paralichthys olivaceus. Sci Rep. 2016;6:35776.

28. Hou J, Wang GX, Zhang XY, Sun ZH, Liu HJ, Wang YF. Cold-shock induced androgenesis without egg irradiation and subsequent production of doubled haploids and a clonal line in Japanese flounder, Paralichthys olivaceus. Aquaculture. 2016;464:642-6.

29. Shao CW, Bao BL, Xie ZY, Chen XY, Li B, Jia XD, Yao QL, Ortí G, Li WH, Li XH, Hamre K, XU J, Wang L, Chen FY, Tian YS, Schreiber AM, Wang N, Wei F, Zhang JL, Dong ZD, Gao L, Gai JW, Sakamoto T, Mo SD, Chen WJ, Shi Q, Li H, Xiu YJ, Li YZ, Xu WT, Shi ZY, Zhang GJ, Power DM, Wang QY, Schartl M, Chen SL. The genome and transcriptome of Japanese flounder provide insights into flatfish asymmetry. Nat Genet. 2017;49:119-24.

30. Sekino M, Hara M, Taniguchi N. Loss of microsatellite and mitochondrial DNA variation in hatchery strains of Japanese flounder Paralichthys olivaceus. Aquaculture. 2002;213:101-22.

31. Li HG, Luo W, Wang Q, Yu XB. Direct fermentation of gelatinized cassava starch to acetone, butanol, and ethanol using Clostridium acetobutylicum mutant obtained by atmospheric and room temperature plasma. Appl Biochem Biotechnol. 2014;172:3330-41.

32. Liu XL, Shen Y, Zhai ZH. A new method for extracting the dinoflagellate Crypthecodinium cohnii chromosomes and observation of their ultrastrcture. Acta Biologiae Experimentalis Sinca. 2000;33:189-93.

33. Kienzler $A$, Tronchère $X$, Devaux $A$, Bony $S$. UV-induced nucleotide excision repair (NER) and photoreactivation repair (PER) in two trout fish cell lines used in ecotoxicological assessment studies. J Photochem Photobio B. 2013; 125:51-5.

34. Olson MH, Mitchell DL. Interspecific variation in UV defense mechanisms among temperate freshwater fishes. Photochem Photobiol. 2006;82:606.

35. Komen $\mathrm{H}$, Thorgaard GH. Androgenesis, gynogenesis and the production of clones in fishes: a review. Aquaculture. 2007;269:150-73.

36. Liu YX, Wang GX, Liu Y, Hou JL, Wang YF, Si F, Sun ZH, Zhang XY, Liu HJ. Production and verification of heterozygous clones in Japanese flounder, Paralichthys olivaceus by microsatellite marker. Afr J Biotechnol. 2011;10: 17088-94.

37. Griffiths, AJF, Wessler SR, Carroll SB, Doebley J. Introduction to genetic analysis. 10th edition. 2012; 630.

38. Riley BB, Grunwald DJ. Efficient induction of point mutations allowing recovery of specific locus mutations in zebrafish. Proc Natl Acad Sci. 1995; 92:5997-6001.

39. Shima A, Shimada A. The Japanese medaka, Oryzias latipes, as a new model organism for studying environmental germ-cell mutagenesis. Environ Health Perspect. 1994;102:33-5.

40. Cheng ZX, Lin JC, Lin TX, Xu M, Huang ZW, Yang ZJ, Huang XY, Zheng JG. Genome-wide analysis of radiation-induced mutations in rice (Oryza sativa L. ssp. indica). Mol BioSyst. 2014;10:795.

41. Adewoye AB, Lindsay SL, Dubrova YE, Hurles ME. The genome-wide effects of ionizing radiation on mutation induction in the mammalian germline. Nat Commun. 2015;6:6684.

42. Liu YX, Wang GX, Liu YJ, Hou JL, Wang YF, Si F, Sun ZH, Zhang XY, Liu HJ. Genetic verification of doubled haploid Japanese flounder, Paralichthys olivaceus by genotyping telomeric microsatellite loci. Aquaculture. 2012; 324-325:60-3.

43. Li H, Durbin R. Fast and accurate short read alignment with burrowswheeler transform. Bioinformatics. 2009;25:1754-60.

44. Li H, Handsaker B, Wysoker A, Fennell T, Ruan J, Homer N, Marth G, Abecasis G. Durbin R. 1000 genome project data processing subgroup. The sequence alignment/map format and SAMtools. Bioinformatics. 2009;25:2078-9.
45. Wang K, Li M, Hakonarson H. ANNOVAR: functional annotation of genetic variants from high-throughput sequencing data. Nucleic Acids Res 2010;38:e164-4.

46. Ye J, Fang L, Zheng H, Zhang Y, Chen J, Zhang ZJ, Wang J, Li ST, Li RQ, Bolund L, Wang J. WEGO: a web tool for plotting GO annotations. Nucleic Acids Res. 2006;34:W293-7.

47. R: A language and environment for statistical computing. Vienna, Austria: $R$ Foundation for Statistical Computing; 2012. Available from: http://www.Rproject.org/.

\section{Ready to submit your research? Choose BMC and benefit from:}

- fast, convenient online submission

- thorough peer review by experienced researchers in your field

- rapid publication on acceptance

- support for research data, including large and complex data types

- gold Open Access which fosters wider collaboration and increased citations

- maximum visibility for your research: over $100 \mathrm{M}$ website views per year

At BMC, research is always in progress.

Learn more biomedcentral.com/submissions 